\title{
Investigation of Diesel Injector Flow Pattern Based On Computer-aided Design
}

\author{
Mohd Azahari Razali ${ }^{1,}{ }^{*}$, Rais Hanizam Madon ${ }^{1}$, Md Norrizam Mohmad Ja'at ${ }^{1}$, Azwan Sapit ${ }^{1}$, \\ Hamidon Salleh ${ }^{1}$, Mohd Faisal Hushim ${ }^{1}$, Waseem Alwan Zaboon², Muhammad Fauzi Samsubaha ${ }^{2}$ \\ 1 Centre for Energy and Industrial Environment Studies (CEIES), Faculty of Mechanical \& Manufacturing Engineering, Universiti Tun Hussein Onn \\ Malaysia, 86400 Pt. Raja, Batu Pahat, Johor, Malaysia \\ 2 Faculty of Mechanical \& Manufacturing Engineering, Universiti Tun Hussein Onn Malaysia, 86400 Pt. Raja, Batu Pahat, Johor, Malaysia
}

\section{ARTICLE INFO}

Article history:

Received 18 March 2020

Received in revised form 17 May 2020

Accepted 22 May 2020

Available online 30 May 2020

\section{Keywords:}

Diesel Fuel Injection; Injector Nozzle Cavitation; CFD ANSYS

\section{ABSTRACT}

Improvements in the diesel fuel injection systems can provide efficient combustion in internal combustion engine. However, the detail relationship between the diesel injector nozzle cavitation parameters are still remain unclear. The main goal of this research is to verify the flow characteristics inside the fuel injector nozzle by using CFD. A computational fluid dynamics cavitation models of diesel injector nozzles is presented and tested. Then, the experimental data are used to validate the models. The researcher used the same shape configeration and boundary condition. The injection event is inherently transient, as the injection pressure varies with the needle lift position. In order to capture this transient aspect within a steady-state formulation, this study performed simulations for different lift positions for the base nozzle. The results is done for the flow distribution for needle lift positions at 0.275 $\mathrm{mm}, 0.2 \mathrm{~mm}, 0.15 \mathrm{~mm}$, and $0.1 \mathrm{~mm}$. The corresponding velocity vector is plotted in order to explain the transient cavitation behavior. The velocity vectors for needle lift $=0.275 \mathrm{~mm}$ indicate that the flow entering the orifice encounters a sharp bend (i.e., large velocity and pressure gradients) at the top of the orifice inlet causing cavitation in this region, However, with needle lift position at $0.15 \mathrm{~mm}$, the flow entrance into the orifice is relatively smooth.

Copyright $@ 2020$ PENERBIT AKADEMIA BARU - All rights reserved

\section{Introduction}

A diesel engine has been wildly used in the fields that require their high torque output and reliability for a long time such as heavy equipment and truck. The use of this type of engines face two major challenges; the first challenge is increased energy efficiency and the other one is lower emissions. Internal combustion engines are significant contributors to the environment pollution that involve a harmful effect on human health and the air [1-3]. Therefore, in designing field, the engine performance takes priority.

\footnotetext{
* Corresponding author.

E-mail address: azahari@uthm.edu.my (Mohd Azahari Razali)
} 
The nozzle of the engine represents one of the most important part in the present system. It controls the combustion and ignition process of the engine system. The ignition process inside the combustion chamber occurs when the fuel is inserted at high pressure through the hot compressed air inside the cylinder in a position near the end of the compression stroke. This process observe the fuel injection features and considered an essential stage process [4-6].

The diesel injection system involves an injection system that inserts the fuel into the engine combustion chamber at the right time, high pressure and with the right quantity. The nozzle represents the most important part in this system [7-9]. The nozzle involves specific holes to spread the fuel into the chamber, therefore the size and number of holes represent an essential part of the nozzle. The designed based on the chamber size, air swirl behavior inside the chamber and the engine torque. For direct injection diesel engine, there are two main nozzle types, the sac hole nozzle and the valve covered orifice nozzle (VCO) [10].

The increase of distance between the needle seat and the hole position of the injector, the radial motion of the needle tip does not change the fuel flow characteristics through the injector hole's motion and fuel spread inside the chamber. That means the fuel flow will be symmetric overall the injector spray. The uncontrollable charges variation produces due to the differences in the nozzle holes and produces a strong change in the overall spray [11].

The high performance of the fuel/air mixture produces a lean of the diesel engine. This mixture produces a significant effect on fuel atomization and burning results [12-17]. The lean mixture can be produced based on the fuel characteristics through the injection process. The affected factors in this process are the nozzle shape design, injected pressure, fuel temperature the combustion environment characteristics such as the ambient temperature and pressure in addition to the burning specification. Many researchers considered the nozzle geometry is the core of these factors [18-24]. It affects and controls the fuel flow characteristics based on the cavity specifications and dimensions. The previous studies and experiment concluded with different shape design can present different spray and can improve engine performance. The major challenge is to find the optimal nozzle geometrical shape design of a diesel engine. The computer-aided design will provide the predicted results and present the flow behavior of fuel.

From this point of view, the present research will investigate the ways to enhance the fuel mixture based on the nozzle geometrical design specification. However, before the improvement in the nozzle geometrical design specification, it is essential to verify the model for diesel injector flow pattern; which is the objective of this study. The study consists of a three-dimensional computeraided design using Solid Work and ANSYS 19.1.

\section{Methodology}

The recent contributions in the present work represent the verification for the simulation of the fuel behavior in the head of the nozzle and specifically in the tip. The flow in this area results in a turbulent flow, inherent instability, and aerodynamic changes. These changes caused by cavitation patterns inside the orifice of the nozzle injector. This part describes the methodology and procedure throughout the project in order to verify the behavior of injected fuel using computational fluid dynamics technique. The different numerical methods and a number of computerized algorithms applied in order to solve and analyses problems that involve the flow of fuel. This work aims to produce a numerical model capable to predict fuel characteristics in a simulated nozzle in order to investigate the behavior of the diesel and biodiesel in different conditions. The calculations require simulating the interaction of fuels with different effective parameters and initial conditions are done by the CFD. The methodology procedure in this work will 
test the model by discretized the partial differential equations into a set of finite controllable volumes that.

\subsection{Modelling Procedure}

The research methodology described in the present work is generated by Solid Work software and transferred to the CFD program as a model of the diesel fuel nozzle. Two different modeling approaches are employed. The first is the 2D model presented by Som et al., [25] in order to investigate the flow behavior through the nozzle cavity. The second model is a 3D tip nozzle which is built using Andsaler et al., [24]. This model presented due to the large varieties in the injection system. These two differ fundamentally in the way they approach the problem. The first model relies on a detailed CFD mesh through the nozzle cavity in order to be able to model the boundary layer phenomena correctly and employs the traditional approach. The second model, on the other hand, relies on the mixture formation of the ignition process which represents a key element in the diesel combustion as it influences the combustion process and exhaust emission.

In SolidWorks, drawings are the 2D documents that you create from 3D part or assembly models. The tools that are considered drawing tools in 2D programs are sketching tools. When developing models in SolidWorks, the sketch geometric entities (such as rectangles and circles) represent the basis for solid features. Based on the real dimensions, the drawing is created by Solid Work program as shown in Figures 1 and 2. In order to convert the 2D drawing to 3D element, the base feature for that is the REVOLVE. Configurations in SolidWorks allow creating multiple variations of a part or assembly model within a single document. Configurations are a convenient way to develop and manage families of models with different dimensions, components, or other parameters.

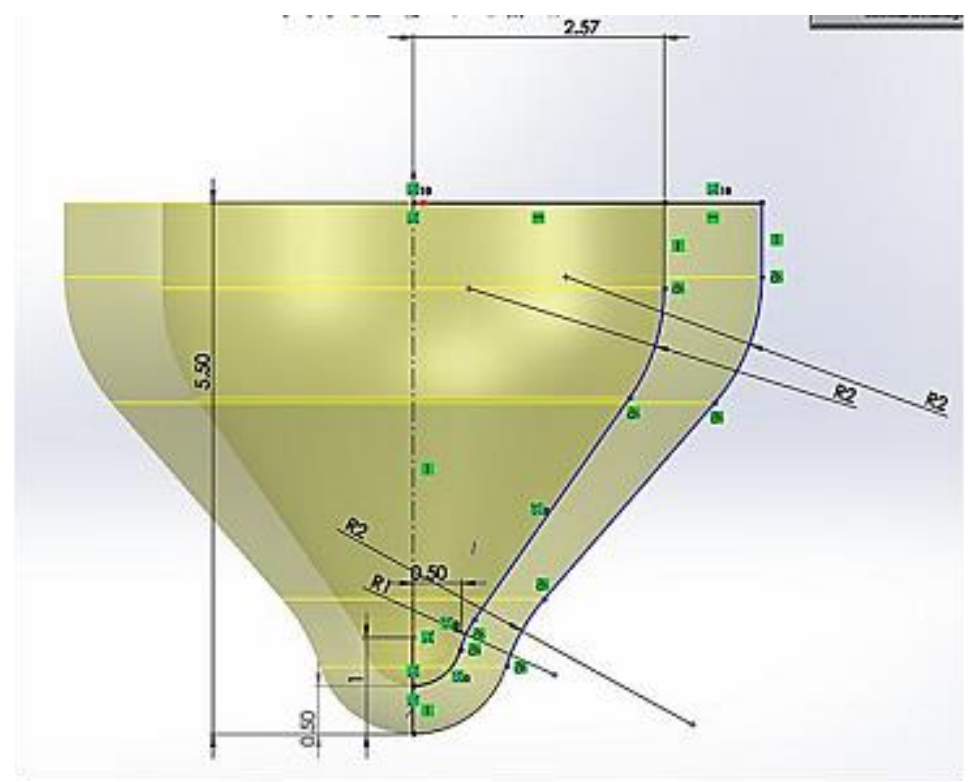

Fig. 1. Nozzle head 


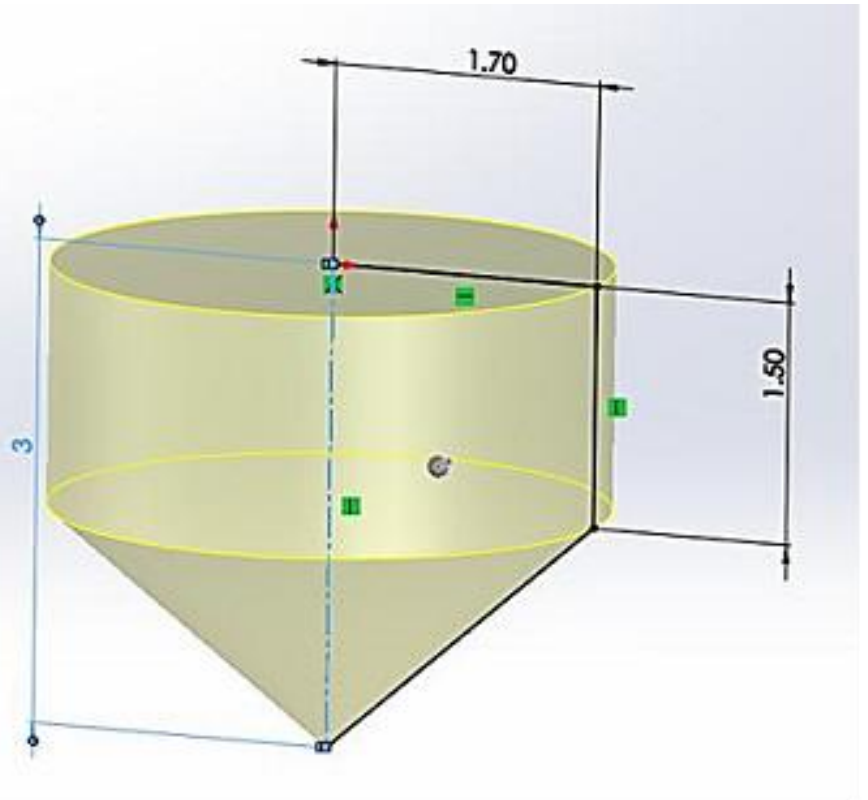

Fig. 2. Needle tip

After creating these two basic elements, the assembly can be performed based on the selected surfaces of the two elements. Figures 3 and 4 observe the 3D nozzle parts and section of the assembly.

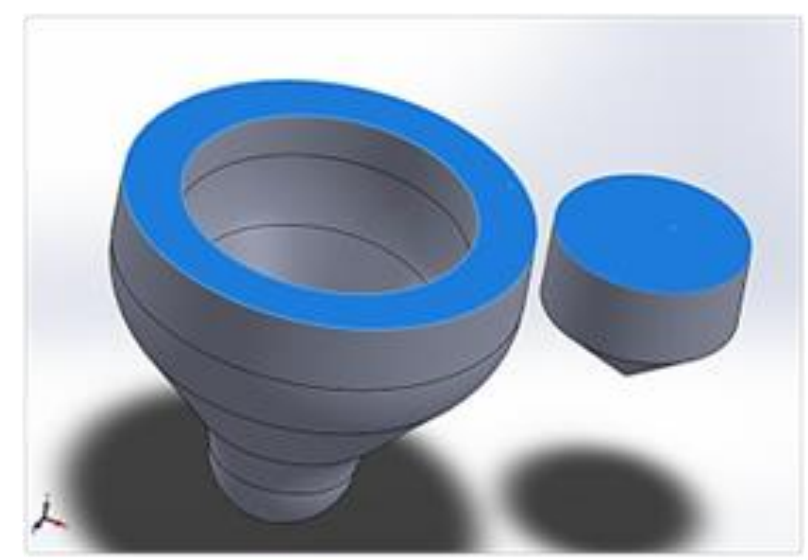

Fig. 3. 3D nozzle parts

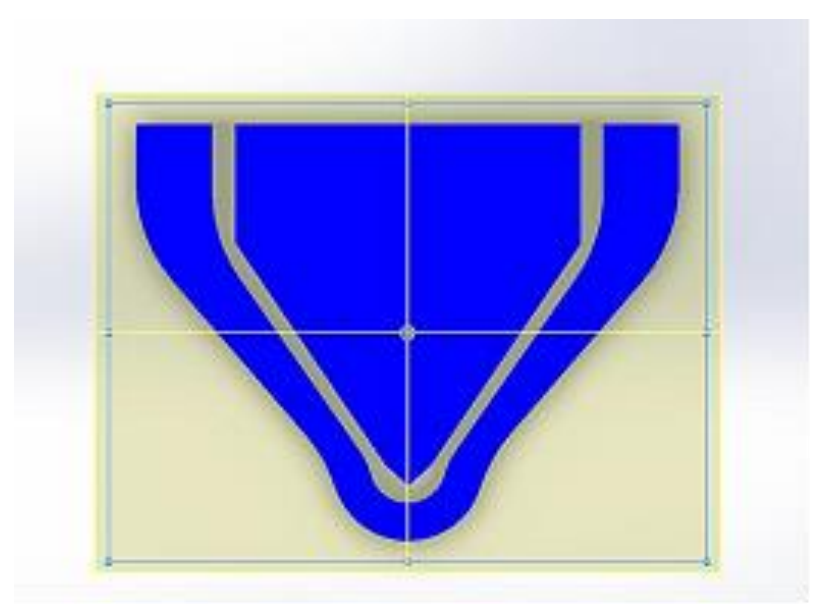

Fig. 4. Section of the assembly 
For 2D simulation, the nozzle injector section can be shown in Figure 5. This part of the study is focused on the flow characteristics based on different needle profile dimensions as presented by Som et al., [25].

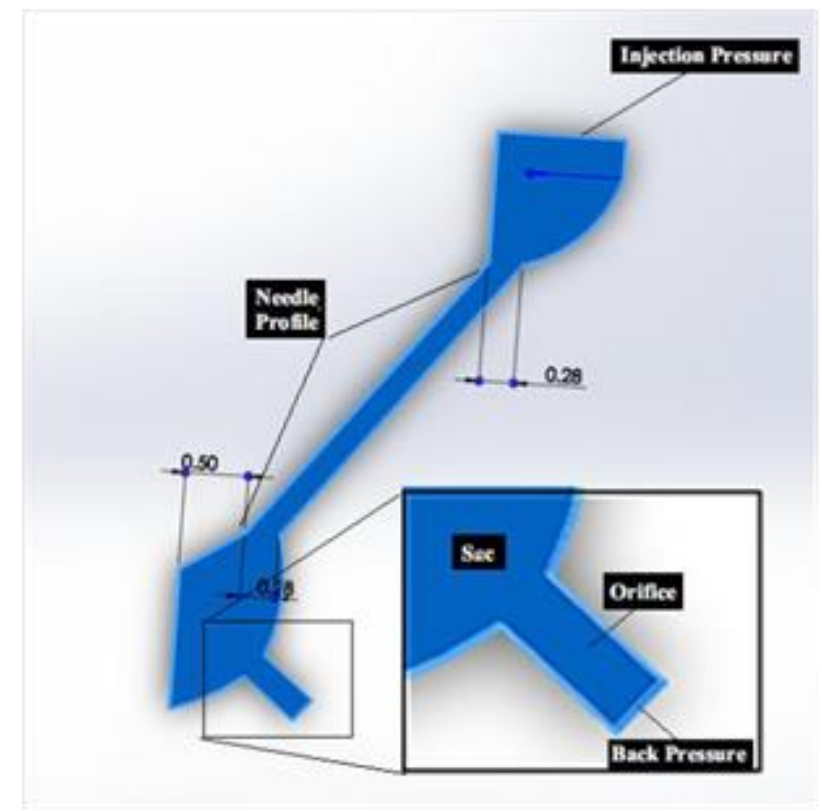

Fig. 5. 2D Nozzle tip configuration

\subsection{Computational Fluid Dynamics (CFD)}

CFD modeling was performed using the ANSYS FLUENT 16.2 CFD software. Computational fluid dynamic uses numerical methods and algorithms to solve and analyze problems that involve fluid flows. Computers are used to perform the calculations required to simulate the interaction of fuels, which defined by boundary conditions. With high-speed supercomputers, better solutions can be achieved. On-going research yields software that improves the accuracy and speed of complex simulation scenarios such as transonic or turbulent flows. ANSYS Workbench is composed of multiple data-integrated and native applications in a single, seamless project flow, where individual cells can obtain data from other cells and provide data to other cells. The first step concerns with creating the geometry as shown in Figure 6.

In order to generate a computational mesh throughout the flow volume, it must use the ANSYS Meshing application to create a mesh for the CFD analysis. Meshing is defined as the process of dividing the whole component into a number of elements so that whenever the load is applied to the component it distributes the load uniformly called as meshing. The mesh elements can be used of the tetrahedral. To create a mesh, either the element count (number of elements) or the element size can be specified. The size functions allow us to control the size of mesh-element edges for the geometric edges, faces or volumes that are meshed. The finer the mesh is better for analysis since it gives us more points to study the behaviour of parameters. When the mesh applied, the naming of the geometric elements applied. To simplify the work later on in ANSYS Fluent, all the surfaces should be labeled in each boundary of the geometry by using the name selections as shown in Figure 7.

Meshing results measure the level of difficulty encountered in meshing the geometry. Meshing complexity involves the translation of these difficulties into a metric that quantifies them. For instance, there are many geometries that have extremely geometrically complex curves and 
surfaces, but are meshed trivially. Likewise, one could easily construct a model using linear curves and planar surfaces that are nearly impossible to mesh. For that, the metric can be used to identify invalid as well as potential poor quality elements, which may cause larger solution errors. The standard ANSYS mesh quality presents that $(0.5$ to 0.8$)$ can be considered as a good result based on scans statues, and the researcher achieves (0.79) mesh quality. Figure 8 presents the basic features of the model considered in the number of nodes and elements.

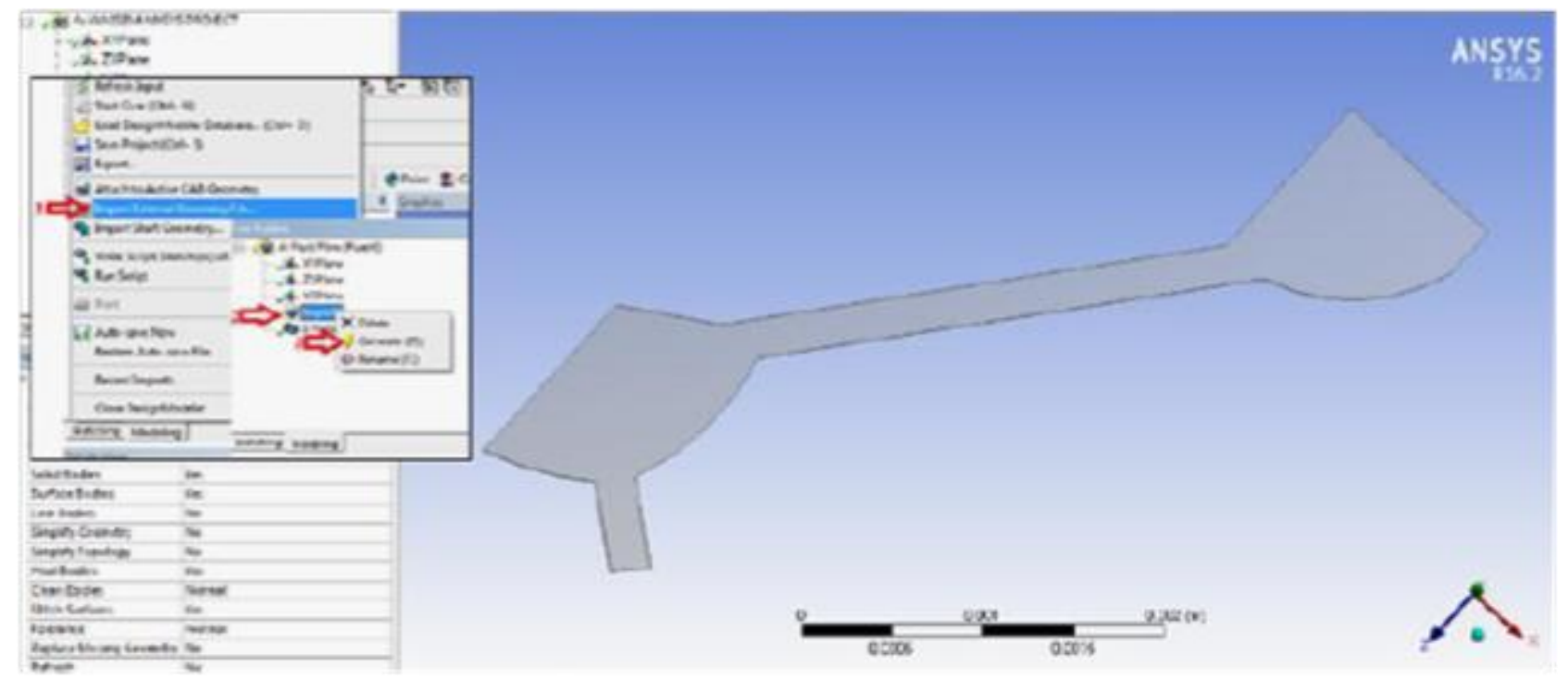

Fig. 6. Imported Geometry

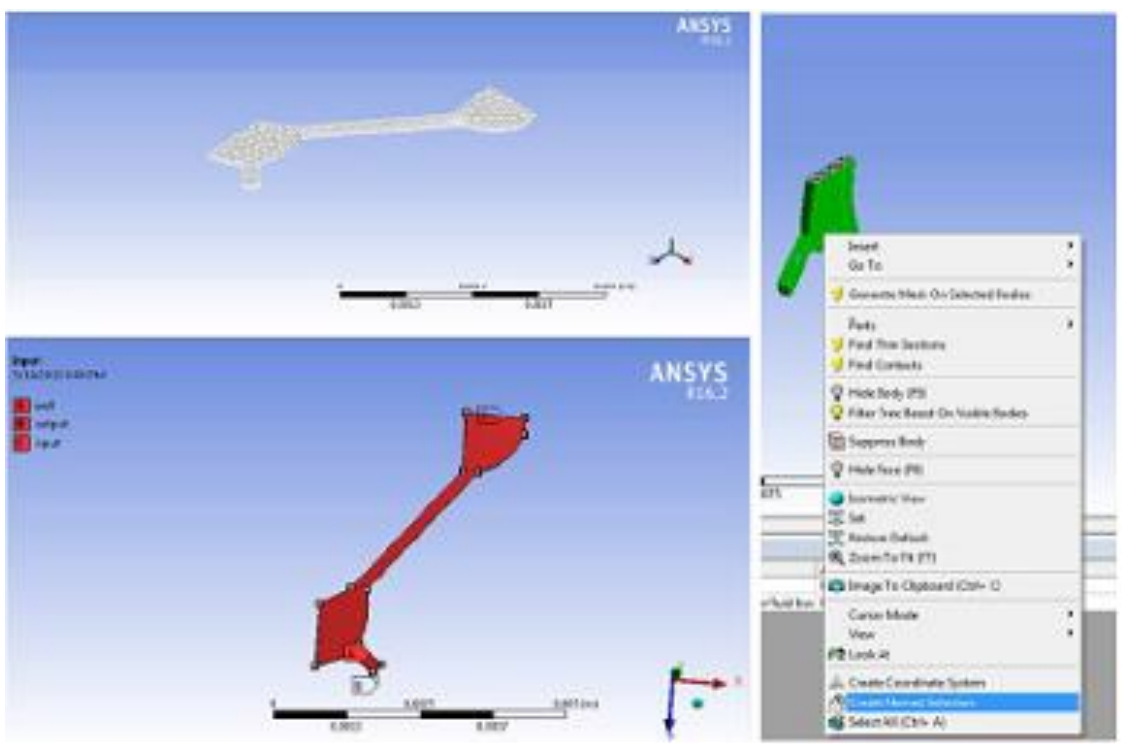

Fig. 7. Mesh results

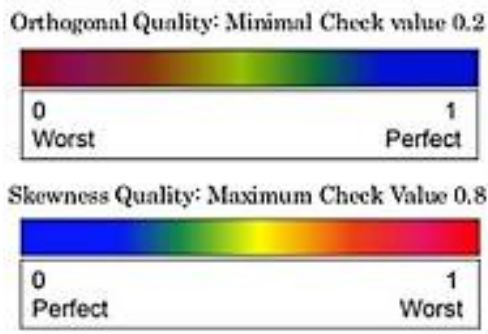

Fig. 8. Mesh matric evaluation 


\section{Results and Discussion}

This section presents the validation and verification of the case study. The experimental data are used to validate the models taken from Som et al., [25]. Figure 9 shows the comparison between the present study and Som et al., [25]. The researcher used the same shape, configuration, and boundary condition. Because of the necessity to model the flow in diesel injector in different cases, it is necessary to consider the accuracy of the CFD method with the help of experimental data. The validation test is a method to minimize and quantify modeling errors and ensure that the CFD model being solved is a good representation of reality. In order to examine the effect of the variation of any particular parameter in the simulation, the sensitivity study is the first which has to be done before the validation. In this study, the sensitivity analyses have been performed to node number, grid types and turbulence models. In order to perform to the sensitivity study of the turbulent flow, the appropriate approach for the flow variables must to specify.

In this section, the experimental results have been performed by applying the different mass flow of diesel. The computational domain can be considered as a two-dimensional region. The model describes a turbulent flow with different needle position. In order to obtain discharge coefficient data, the properties of different fuels are listed in Table 1 . The initial amplitude parameter as defined by Li et al., [26] is used to characterize the level of turbulence at the nozzle exit.

Table 1

Comparison Contours of Different Number of Blade

\begin{tabular}{lllll}
\hline Property & $\begin{array}{l}\text { Viscor/cerium } \\
\text { blend }\end{array}$ & $\begin{array}{l}\text { European } \\
\text { diesel No. 2 }\end{array}$ & $\begin{array}{l}\text { Chevron diesel } \\
\text { No. 2 }\end{array}$ & Dodecane \\
\hline Density $\left(\mathrm{kg} / \mathrm{m}^{3}\right)$ & 865.4 & 835.0 & 822.7 & 745.7 \\
Viscosityu $(\mathrm{kg} / \mathrm{ms})$ & 0.0029 & 0.0025 & 0.0021 & 0.0014 \\
Surface Tension $(\mathrm{N} / \mathrm{m})$ & 0.026 & 0.020 & 0.020 & 0.0025 \\
Vapor Pressure $(\mathrm{Pa})$ & 1057 & 1000 & 1000 & 40 \\
\hline
\end{tabular}

The injection event is inherently transient, as the injection pressure varies with the needle lift position. In order to capture this transient aspect within a steady-state formulation, this study performed simulations for different lift positions for the base nozzle. Figure 10 presents the flow distribution for needle lift positions at $0.275 \mathrm{~mm}, 0.2 \mathrm{~mm}, 0.15 \mathrm{~mm}$, and $0.1 \mathrm{~mm}$. In order to explain the transient cavitation behavior, Figure 11 presents the corresponding velocity vector plots. The velocity vectors for needle lift $=0.275 \mathrm{~mm}$ indicate that the flow entering the orifice encounters a sharp bend (i.e., large velocity and pressure gradients) at the top of the orifice inlet causing cavitation in this region, However, with needle lift position at $0.15 \mathrm{~mm}$, the flow entering into the orifice is relatively smooth. This is due to the fact that the flow is restricted between the needle and nozzle wall, and a sudden expansion result in a recirculation zone downstream of the restriction.

This causes the velocity vectors to be aligned in a manner that the entry to the nozzle orifice is smooth thus inhibiting cavitation. Further downward movement of the needle (needle lift $=0.1 \mathrm{~mm}$ ) results in a stronger recirculation zone. The velocity vectors are aligned such that the entry at the orifice top is smooth, but the entry at the orifice bottom is sharp causing cavitation in the bottom region, although the velocity vectors encounter a sharp bend, the gradients are not sufficiently large to cause cavitation. 
Figure 9 also presents a compression of the global nozzle characteristics in terms of discharge coefficient and lift position for the discussed cases. The results correspond to the full open needle position and indicate that $\mathrm{Cd}$ is essentially independent of the peak injection pressure, irrespective of the needle lift position.

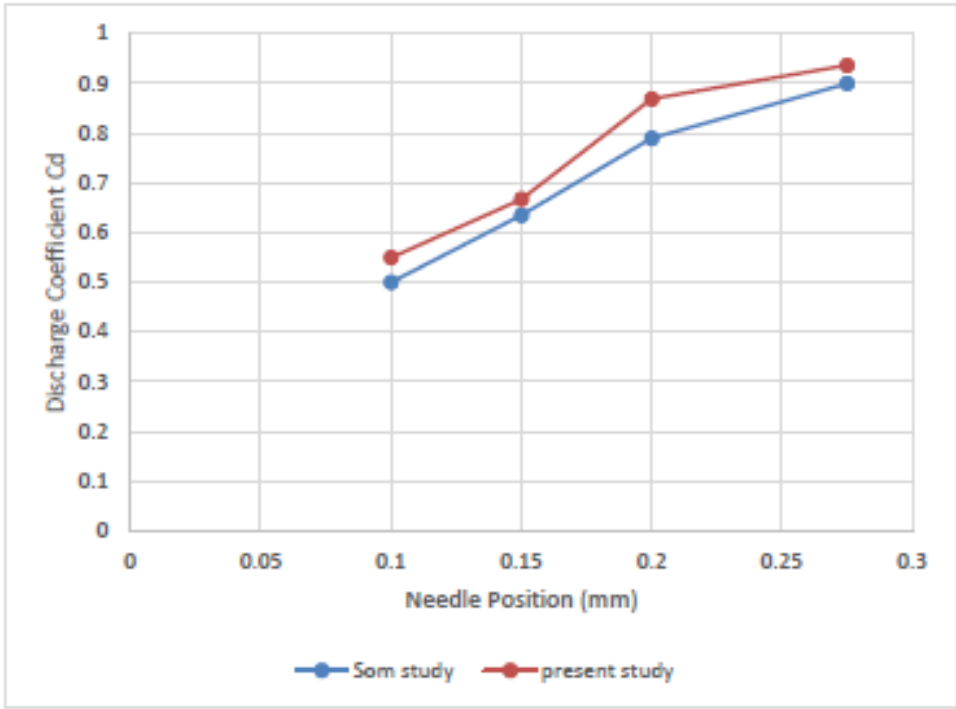

Fig. 9. Data comparison between present study and Som et al., [25]

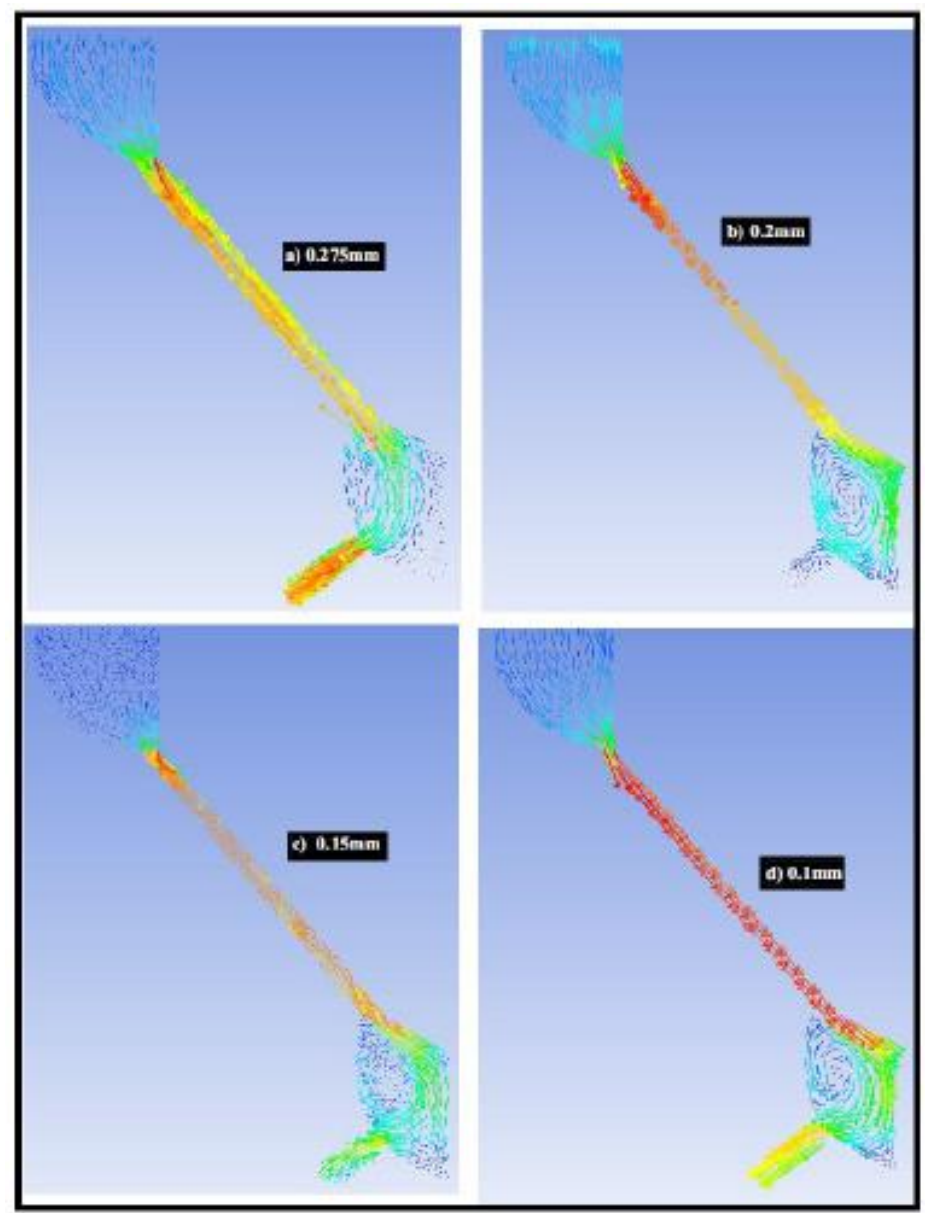

Fig. 10. Flow profile at different needle lift positions: a) $0.275 \mathrm{~mm} \mathrm{b)} 0.2 \mathrm{~mm}$ c) $0.15 \mathrm{~mm} \mathrm{d)} 0.1 \mathrm{~mm}$ 


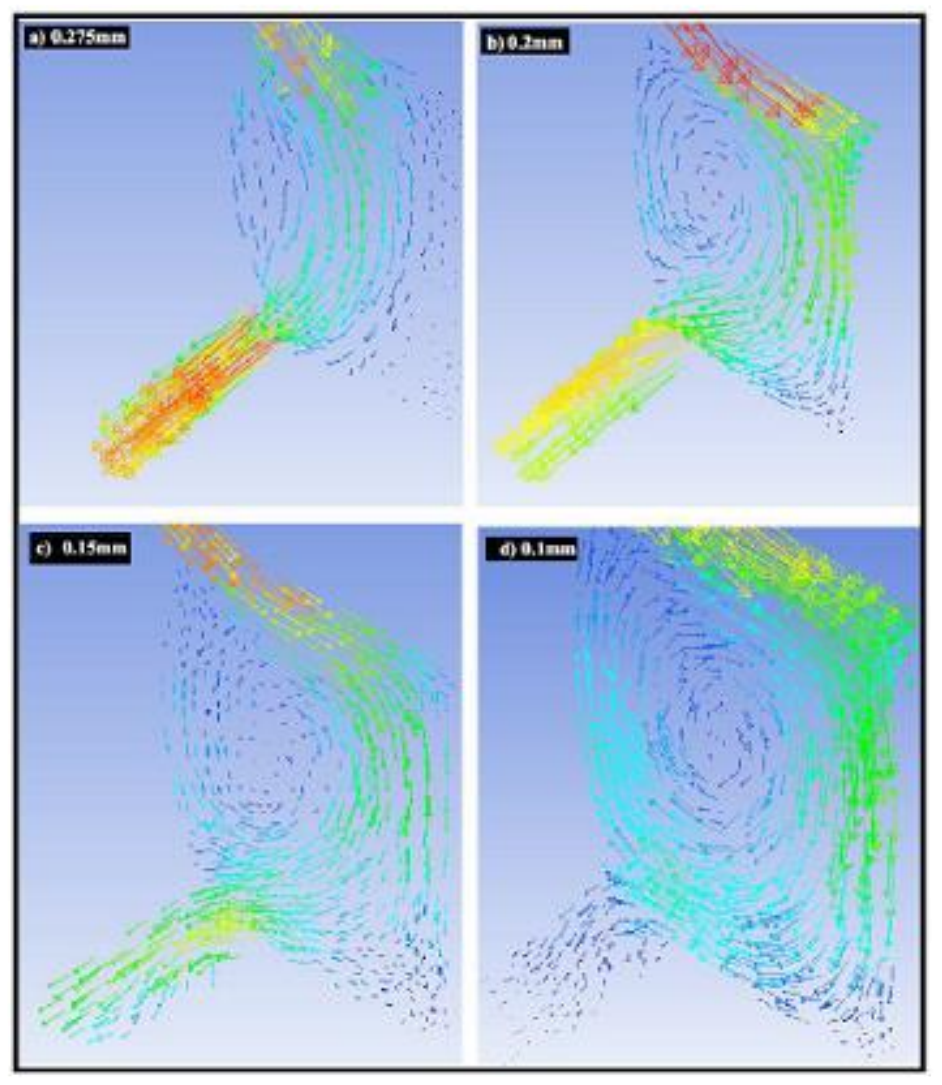

Fig. 11. The velocity vectors a) $0.275 \mathrm{~mm} \mathrm{b)} 0.2 \mathrm{~mm} \mathrm{c)} 0.15$ $\mathrm{mm}$ d) $0.1 \mathrm{~mm}$

\section{Conclusions}

The conclusions obtained in the present study are as follows:

I. The simulation of the fuel behavior in the head of the nozzle and specifically in the tip. The velocity vectors for needle lift $=0.275 \mathrm{~mm}$ indicate that the flow entering the orifice encounters a sharp bend (i.e., large velocity and pressure gradients) at the top of the orifice inlet causing cavitation in this region, However, with needle lift position at $0.15 \mathrm{~mm}$, the flow entering into the orifice is relatively smooth.

II. The results indicate that $\mathrm{Cd}$ is essentially independent of the peak injection pressure, irrespective of the needle lift position.

\section{Acknowledgement}

The authors would like to thank Universiti Tun Hussein Onn Malaysia (UTHM) and Ministry of Higher Education Malaysia (MOHE) for their financial support of the present work through GPPS Grant Scheme (U802) and Fundamental Research Grant Scheme (FRGS-1465 and FRGS-1545), respectively.

\section{References}

[1] Tahmasebi, Ehsanallah. "Simulation of internal flow in fuel injection process." PhD diss., Italy, 2017.

[2] Khalid, Amir, Ridwan Saputra Nursal, Ahmad Syukri Ahmad Tajuddin, Syahrunniza Abd Hadi. "Performance and emissions characteristics of alternative biodiesel fuel on small diesel engine." ARPN Journal of Engineering and Applied Sciences 11, no. 12 (2016): 7424-7430. 
[3] Khalid, A., A. S. A. Tajuddin, N. Jaat, B. Manshoor, I. Zaman, S. A. A. Hadi, and R. S. Nursal. "Performance and emissions of diesel engine fuelled with preheated biodiesel fuel derived from crude palm, jatropha, and waste cooking oils." International Journal of Automotive and Mechanical Engineering 14 (2017): 4273-4284.

[4] Bastawissi, Hagar Alm-Eldin, and Medhat Elkelawy. "Investigation of the flow pattern inside a diesel engine injection nozzle to determine the relationship between various flow parameters and the occurrence of cavitation." Engineering 6, no. 13 (2014): 923 - 935. https://doi.org/10.4236/eng.2014.613084

[5] Khalid, Amir, Azim Mudin, M. Jaat, Norrizal Mustaffa, Bukhari Manshoor, Mas Fawzi, Mohd Azahari Razali, and Mohd Zamani Ngali. "Effects of biodiesel derived by waste cooking oil on fuel consumption and performance of diesel engine." In Applied Mechanics and Materials, vol. 554, pp. 520-525. Trans Tech Publications Ltd, 2014. https://doi.org/10.4028/www.scientific.net/AMM.554.520

[6] Khalid, Amir, and Bukhari Manshoor. "Effect of high swirl velocity on mixture formation and combustion process of diesel spray." In Applied Mechanics and Materials, vol. 229, pp. 695-699. Trans Tech Publications Ltd, 2012.

[7] Win, Z., R. P. Gakkhar, S. C. Jain, and M. Bhattacharya. "Investigation of diesel engine operating and injection system parameters for low noise, emissions, and fuel consumption using Taguchi methods." Proceedings of the Institution of Mechanical Engineers, Part D: Journal of Automobile Engineering 219, no. 10 (2005): 1237-1251. https://doi.org/10.1243/095440705X34865

[8] Azwan Sapit, Mohd Azahari Razali, Mohd Faisal Hushim, Amir Khalid, Md Norrizam Mohmad Ja'at, Muhammad Fauzi Samsubaha, Tuan Mohamad Kamarul Hisyam Tuan A Talib. "Effect of Acoustic Excitation toward Jet Flame: An Experimental Design." Journal of Advanced Research in Fluid Mechanics and Thermal Sciences 53, no. 1 (2019): 69-74.

[9] Razali, Mohd Azahari, Azwan Sapit, Mohd Faisal Hushim, Amir Khalid, Suzuki Masataro, and Masuda Wataru. "Flame spread behavior over combined fabric of cotton/polyester." In International Engineering Research and Innovation Symposium 2015 (IRIS), 12-13 September 2015.

[10] Lindström, Mikael. "Injector nozzle hole parameters and their influence on real di diesel performance." PhD diss., KTH, 2009.

[11] Wirth, K-E., and M. Rossmeissl. "Critical mass-flow in orifice-nozzles at the disintegration of superheated liquids." In ASME 2006 2nd Joint US-European Fluids Engineering Summer Meeting Collocated With the 14th International Conference on Nuclear Engineering, pp. 1381-1388. American Society of Mechanical Engineers Digital Collection, 2006.

[12] Payri, Raul, Francisco Javier Salvador, Jaime Gimeno, and Juan P. Viera. "Experimental analysis on the influence of nozzle geometry over the dispersion of liquid n-dodecane sprays." Frontiers in Mechanical Engineering 1 (2015): 13. https://doi.org/10.3389/fmech.2015.00013

[13] Chua, B. L., Akmal Nizam, M., Azwan, S., Mohd Azahari, R., Mohd Faisal, H., Amir, K., \& Nurul Farhana, M. Y. 2020. "Numerical Simulation of Aerofoil with Flow Injection at the Upper Surface." CFD Letters, 12, no. 1 (2020): 98-110.

[14] MIT. (2008). Diesel Injection, Ignition, and Fuel Air Mixing. MIT OpenCourseWare.

[15] Razali, Mohd Azahari bin, Azwan bin Sapit, Akmal Nizam Mohammed, Mohd Faisal Bin Hushim, Hamidon bin Salleh, and Hazahir bin Peraman. "Effect of thread angle on flame spread behaviour over combined fabric of kenaf/polyester." In AIP Conference Proceedings, vol. 1831, no. 1, p. 020016. AIP Publishing LLC, 2017. https://doi.org/10.1063/1.4981157

[16] Ramli, Afifah, Mohd Azahari Razali, Rais Hanizam Madon, Mohd Faisal Hushim, Amir Khalid, Md Norrizam Mohmad Ja'at, and Hamidon Salleh. "Influence of Material Composition on Flame Spread Behaviour over Combustible Solid of Paper/Bagasse." International Journal of Integrated Engineering 10, no. 8 (2018): $142-146$.

[17] Razali, Mohd Azahari, Azwan Sapit, Akmal Nizam Mohammed, Mohd Faisal Hushim, Azmahani Sadikin, Md Norrizam Mohmad Ja'at, Hazahir Peraman, and Mirnah Suardi. "Flame Spread Behavior over Kenaf Fabric, Polyester Fabric, and Kenaf/Polyester Combined Fabric." In Engineering Applications for New Materials and Technologies, pp. 67-75. Springer, Cham, 2018. https://doi.org/10.1007/978-3-319-72697-7 5

[18] Yii Shi Chin, Ronny, Shahrin Hisham Amirnordin, N. O. R. A. N. I. Mansor, and Amir Khalid. "Numerical Analysis of Nozzle Hole Shape to the Spray Characteristics from Premix Injector in Burner System: A Review." In Applied Mechanics and Materials, vol. 773, pp. 610-614. Trans Tech Publications Ltd, 2015. https://doi.org/10.4028/www.scientific.net/AMM.773-774.610

[19] Tu, Powen. "Numerical and experimental study of spray characteristics in the gasoline direct injection engine." PhD diss., University of Birmingham, 2016. 
[20] Ghurri, Ainul, Jae-Duk Kim, Hyung Gon Kim, Jae-Youn Jung, and Kyu-Keun Song. "The effect of injection pressure and fuel viscosity on the spray characteristics of biodiesel blends injected into an atmospheric chamber." Journal of mechanical science and technology 26, no. 9 (2012): 2941-2947.

https://doi.org/10.1007/s12206-012-0703-1

[21] Ramli, Afifah, Mohd Azahari Razali, Azwan Sapit, Mohd Faisal Hushim, Normayati Nordin, Amir Khalid, and Md Nor Anuar Mohammad. "Flame Spread Behaviour over Combustible Solid of Paper, Bagasse and Paper/Bagasse." In MATEC Web of Conferences, vol. 135, p. 00012. EDP Sciences, 2017. https://doi.org/10.1051/matecconf/201713500012

[22] Azahari, Bin Razali Mohd, Masayuki Mori, Masataro Suzuki, and Wataru Masuda. "Measurement of thermophoretic parameters for binary gas mixtures." Journal of aerosol science 63 (2013): 60-68.

https://doi.org/10.1016/j.jaerosci.2013.05.003

[23] Azahari, Bin Razali Mohd, Masayuki Mori, Masataro Suzuki, and Wataru Masuda. "Effects of gas species on pressure dependence of thermophoretic velocity." Journal of aerosol science 54 (2012): 77-87. https://doi.org/10.1016/i.jaerosci.2012.07.002

[24] Khalid, Amir, Adiba Rhaodah Andsaler, Bukhari Manshoor, and Norrizam Jaat. "Effect of high pressure on the flow characteristics of injector using computational fluid dynamics (CFD)." ARPN Journal of Engineering and Applied Sciences 11, no. 12 (2016): 7503-7506.

[25] Som, S., Suresh K. Aggarwal, E. M. El-Hannouny, and D. E. Longman. "Investigation of nozzle flow and cavitation characteristics in a diesel injector." Journal of Engineering for Gas Turbines and Power 132, no. 4 (2010): 042802. https://doi.org/10.1115/1.3203146

[26] LI, Ming-hai, and Hai-ting YIN. "Improved Structure and Three-dimensional Numerical Analysis of Diesel Nozzle." TELKOMNIKA Indonesian Journal of Electrical Engineering 10, no. 6 (2012): 1364-1369.

https://doi.org/10.11591/telkomnika.v10i6.1401 